\title{
Potencial econômico da geração de energia elétrica por sistema fotovoltaico na universidade pública
}

\section{Economic potential for generation of electric power by photovoltaic system in a public university}

\author{
Arthur Garcia Silveira Graduado, Universidade Estadual Paulista "Júlio de Mesquita Filho" \\ (UNESP), Brasil - arthurgsilveira1@gmail.com \\ David Ferreira Lopes Santos Doutor, Universidade Estadual Paulista "Júlio de Mesquita Filho" \\ (UNESP), Brasil - david.lopes@unesp.br \\ Stela Basso Montoro Mestre, Universidade Estadual Paulista "Júlio de Mesquita Filho" \\ (UNESP), Brasil - stelamontoro@hotmail.com
}

\section{RESUMO}

Este estudo apresenta o potencial econômico da geração de energia elétrica por sistema fotovoltaico em uma universidade pública brasileira com o objetivo, igualmente, de reduzir o maior custo das universidades, após a folha de pagamento e contribuir para uma matriz energética mais sustentável e equilibrada, a partir da disseminação da microgeração ou autossuficiência energética. Postulou-se, também, um plano financeiro estruturado a partir do instituto da parceria público-privada que pode ser empreendido por meio de uma Sociedade de Propósito Específico. A proposta deste projeto tem como base a Faculdade de Ciências Agrárias e Veterinárias (FCAV), Universidade Estadual Paulista "Júlio de Mesquita Filho" (UNESP). Utilizou-se o método do Fluxo de Caixa Descontado para analisar a viabilidade econômica e financeira do projeto. Projetou-se uma estrutura para $5 \mathrm{MW}$ que exigirá um investimento de $\mathrm{R} \$ 25,5$ milhões para instalar painéis solares em uma área próxima a 4 hectares. O modelo apresentou viabilidade econômica para a SPE até o limite de 39,9\% de deságio na tarifa média atual, o que representaria uma economia estimada de R\$1.230.882/ano à FCAV, podendo gerar uma folga no orçamento de custeio da FCAV de $40 \%$.

Palavras-chave: Análise de Investimento. Energia Renovável. Gestão Universitária. Fluxo de Caixa Descontado.

\section{ABSTRACT}

This study presents the economic potential of electric power generation by photovoltaic system in a Brazilian public university with the objective of reducing the second highest cost of universities, after the employee payroll, and also contributing to a more sustainable and balanced energy matrix via micro-generation or energy self-sufficiency. A financial plan was structured through a private public partnership, which may be undertaken by a Specific Purpose Society. The proposal of this project is based on the School of Agrarian and Veterinary Sciences (FCAV), Sao Paulo State University (UNESP). The discounted cash flow method was used to analyze the economic and financial feasibility of the project. The $5 \mathrm{MW}$ projected structure would require a capital expenditure of R\$25.5 million to install solar panels in an area close to 4 ha. The model presented economic feasibility for the SPE up to the limit of $39.9 \%$ discount in the current average tariff, which would represent an estimated saving of R\$1,230,882/year to FCAV, thus generating a financial slack of $40 \%$ in FCAV's cost budget.

Keywords: Investment Analysis. Renewable energy. University Management; Discounted Cash Flow. 


\section{INTRODUÇÃO}

A importância das Instituições de Ensino Superior (IES) públicas para o desenvolvimento econômico é ponto pacífico na literatura (HOFF; PEREIRA; PAULA, 2017), seja pela formação de profissionais para o mercado de trabalho (OLIVEIRA JR., 2014), formação de docentes para a educação básica, profissionalizante e superior (PENIN, 2001), assim como para o fomento à ciência, tecnologia e inovação (FERREIRA; LEOPOLDI, 2013).

No entanto, as características geográficas e demográficas diversas e desiguais que constituem o território brasileiro (CHEIN; LEMOS; ASSUNÇÃO, 2007), associada à inércia da estrutura orçamentária da administração pública (SILVA et al., 2012), bem como, a ineficiência do desempenho da gestão dos recursos públicos nas autarquias limitam a possibilidade de expansão sustentável da universidade pública brasileira (FALQUETO; FARIAS, 2013; RIGHETTI, 2017).

O INEP (2015) computa 295 IES com natureza pública (federal, estadual e municipal), cuja representatividade alcança $12,48 \%$ do total de IES do Brasil, sendo responsáveis por $24,31 \%$ dos alunos de graduação. Os recursos públicos destinados ao ensino superior foram de $\mathrm{R} \$ 77,1$ bilhões em 2016, valor nominal $76 \%$ superior ao gasto em 2010 , sendo que as condições atuais de funcionamento das instituições públicas têm sido caracterizadas como a pior crise financeira para as universidades públicas (RIGHETTI, 2017).

Para que a universidade pública brasileira seja sustentável no longo prazo não apenas na sua expansão quantitativa, mas e, sobretudo, qualitativa, há a necessidade proeminente de melhorar a gestão orçamentária, de modo, a encontrar maior eficiência no gasto do erário público (SILVA et al., 2012). Essa premissa além de ser um princípio no direito administrativo (PEREIRA, 1996), é um ponto que tem se discutido com maior ênfase na literatura especializada em administração pública e, especialmente, na administração universitária (SAMPAIO; LANIADO, 2009).

Todavia, ainda são escassos estudos ou relatos que proporcionem insigths aos gestores e toda a comunidade quanto as práticas que proporcionam maior eficiência no gasto público (PASCUCl et al., 2016; SILVA et al., 2012). Não obstante, esse estudo aborda o principal item de custeio das universidades públicas (após a folha de pagamento) que é a energia elétrica (PEREIRA; SANTOS, 2007).

Em adição a importância sobressalente do custo da energia elétrica no orçamento das universidades públicas, a demanda por energia elétrica é um dos principais temas na agenda da sustentabilidade da sociedade atual (NERES; FERREIRA; SILVA JR., 2012). Essa situação decorre da matriz energética mundial ainda muito dependente de fontes fósseis cujos impactos ambientais são elevados em todo o ciclo de vida deste recurso (GOTZ et al., 2016).

Ainda que a matriz energética brasileira seja baseada em hidroelétricas que respondem por $75 \%$ da demanda de energia elétrica do país, o crescimento da oferta por esta fonte alcança os limites atuais para conservação dos principais biomas brasileiros (EPE, 2016; NERES; FERREIRA; SILVA JR., 2012). Além disso, a dependência dos regimes hidrológicos para a oferta tem ocasionado ao país experiências negativas como no "apagão de 2000" (MOREIRA; DAVID; ROCHA, 2003) e nos dois últimos anos em que os reservatórios estão nos seus menores níveis exigindo o acionamento de fontes térmicas movidas a gás natural, carvão mineral e diesel.

A energia solar ainda é um desafio tecnológico, econômico e cultural para o Brasil, porém em função da sua posição tropical e alta taxa de insolação é um potencial recurso e com exploração insignificante em nossa matriz energética; sendo, contudo, uma das fontes mais sustentáveis entre as alternativas existentes (SILVA, 2015).

A viabilidade econômica de sistemas de geração de energia solar é apontada como uma das principais barreiras à realização do investimento, de modo que o elevado valor do investimento inicial e o período de recuperação dificultam a adoção para a microgeração entre famílias e empresas (VIER et al., 2017; ARAGÓN; PAMPLONA; MEDINA, 2013); essa dificuldade é potencializada pelas linhas de crédito restritas.

O Ministério de Minas e Energia anunciou em 2015 que, em parceria com o Ministério da Educação, a intenção de instalar geração fotovoltaica nos estacionamentos das universidades federais, na busca de reduzir o consumo e "torná-las autossuficientes em eletricidade". Porém, apenas a Universidade Federal do Rio de 
Janeiro já possui o equipamento instalado em alguns dos seus estacionamentos, aquém de sua necessidade total de energia.

Verificou-se que a geração de energia solar em universidades de outros países é uma realidade, como os EUA, em que mais de 10 universidades já possuem elevadas capacidades de geração de energia (MEYER, 2014). Destaca-se a University of Arizona e Northwestern University com geração para 28 MW e 16,8 MW respectivamente (GEOTHERMAL TECHNOLOGIES OFFICE, 2017).

Desta forma, esse estudo se posiciona em um gap teórico e prático para a realidade brasileira quanto a estudos aplicados que demonstrem se há viabilidade econômica na instalação de sistemas para geração de energia solar em universidades públicas brasileiras. Desta forma, o objetivo é analisar o potencial econômico de um sistema fotovoltaico para a realidade da Faculdade de Ciências Agrárias e Veterinárias (FCAV) da Universidade Estadual Paulista "Júlio de Mesquita Filho" (UNESP).

Adicionalmente à análise da viabilidade econômica da geração de energia solar, este trabalho estende a discussão com a proposição de uma estrutura financeira que viabilize o investimento de forma independente de recursos do Estado o que pode permitir a expansão da aplicação sem exigir o recurso do erário público.

\section{MATERIAL E MÉTODOS}

Esta pesquisa se caracteriza como um estudo exploratório com finalidade aplicada, a partir de uma abordagem que congrega elementos qualitativos para o levantamento das informações primárias e quantitativa para a construção do resultado econômico-financeiro. Este estudo teve como estratégia metodológica o estudo de caso, como forma de evidenciar um caso prático e representativo da realidade das universidades públicas brasileiras.

Em que pese a impossibilidade da replicação dos resultados, espera-se que os resultados propostos para este caso específico desperte a atenção de gestores e demais profissionais vinculados ou interessados na gestão universitária, bem como, investidores e empresas que atuam na geração de energia solar.

Os dados primários foram alcançados por meio de entrevista não estruturada com o Diretor de Serviços da Faculdade que disponibilizou as informações brutas quanto ao consumo (demanda da universidade) de energia e valores desembolsados para o pagamento da energia junto à concessionária de energia.

Os dados secundários permitiram a construção do fluxo de caixa, desde a melhor compreensão do sistema por meio da literatura até os valores do investimento e custos de operação tomados junto a um dos principais fornecedores da tecnologia.

Para a realização das análises foram realizadas cotações com três fornecedores para avaliação dos investimentos para criação de uma usina solar fotovoltaica no campus da FCAV/UNESP, além dos custos inerentes. A partir destes dados realizou-se os estudos econômicos a fim de verificar a viabilidade econômica do projeto. $O$ estudo abordou também o campo financeiro, a fim de evidenciar as formas de financiamento disponíveis e se o projeto possui viabilidade financeira. Todo o estudo foi feito com base nos dispositivos legais do instituto da parceria público-privada, de modo que a participação privada contribua na diluição do risco e volume do investimento para a realização do projeto, bem como, servir de alternativa à dependência da disponibilidade de capital do poder público mantenedor da IES.

\section{RESULTADOS E DISCUSSÃO}

Para melhor apresentar os resultados do estudo, essa seção foi sequenciada de modo a permitir inicialmente a contextualização da FCAV dentro da UNESP e suas características físicas e acadêmicas. $\mathrm{Na}$ sequência, todos os resultados necessários ao fluxo de caixa são apresentados de modo analítico para então, ao final, a viabilidade econômica do projeto ser apresentada e discutida. 


\subsection{Contextualização da FCAV}

A UNESP é uma universidade de múltiplos campi e foi classificada como uma das 5 melhores universidades brasileiras no último relatório do Academic Ranking of World University (ARWU, 2016). A FCAV é uma das faculdades mais tradicionais da UNESP e uma das líderes na produção científica e na captação de recursos junto aos órgãos de fomento dentro da universidade. A Figura 1 apresenta um indicador médio de produção ponderado por docente entre a FCAV e a UNESP o que ratifica a importância acadêmica desta faculdade para uma das principais universidades brasileiras e latino-americana.

Figura 1 - Comparativo da Média Ponderada da Produção por Docente entre FCAV e UNESP.

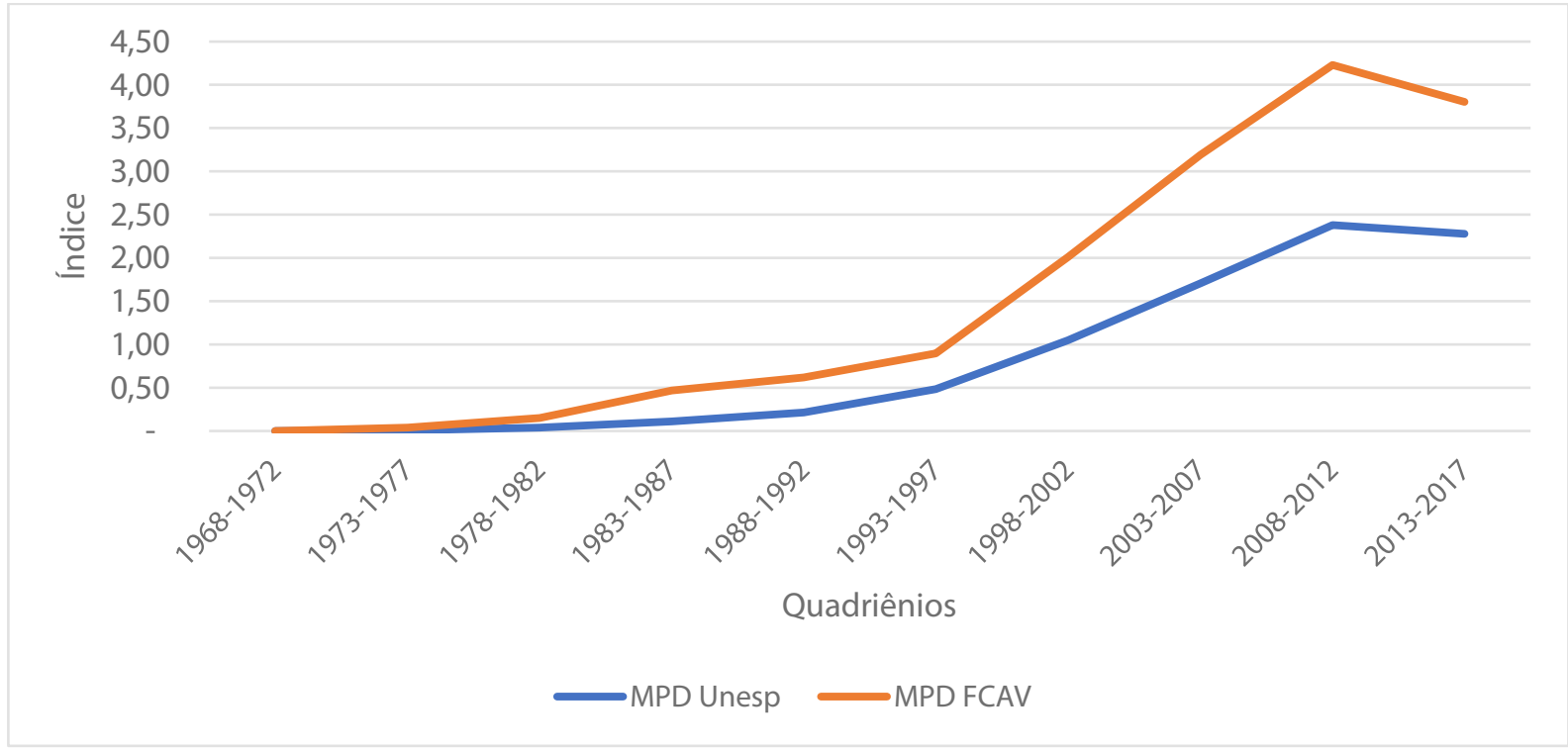

Fonte: elaboração própria, a partir da UNESP (2017).

A FCAV está localizada no município de Jaboticabal - SP, foi fundada em 1966, cerca de dez anos antes da incorporação das instituições de ensino pelo governo do estado de São Paulo, para formação da Universidade Estadual Paulista "Júlio de Mesquita Filho" - UNESP.

A FCAV conta com 1 Colégio Técnico Agrícola, com dois cursos profissionalizante em nível médio, 5 cursos de graduação (Administração, Ciências Biológicas, Engenharia Agronômica, Medicina Veterinárias e Zootecnia), 11 programas de pós-graduação stricto sensu com 21 cursos de mestrado e doutorado. A FCAV iniciou 2017 com 250 docentes/pesquisadores, 483 servidores técnicos/administrativos e mais de 3.000 alunos (FCAV, 2017).

A FCAV possui área total de 829 hectares (ha), sendo que 13 ha são destinados aos prédios e estrutura física do campus, incluindo treze departamentos, salas de aula, prédio da administração, laboratórios, centro de convenções, hospital veterinário e espaço esportivo. Além desta área, o campus conta com 350 ha para produção vegetal (ensino e pesquisa), 225 ha para produção animal (ensino e pesquisa), 102 ha para parques e jardins, e 34 ha de matas naturais e recomposição (FCAV, 2017).

Uma das maiores dificuldades da implantação de placas solares é a necessidade de espaço compatível com a capacidade da instalação do sistema. O campus, além do excesso de espaço disponível, possui áreas destinadas a agricultura, que não possui vegetação nativa perto. Outra vantagem do campus para a instalação é o terreno estar longe de prédios (pelo sombreamento) e casas, levando em consideração a alta voltagem do sistema e a proibição de acesso por pessoas desautorizadas. 


\subsection{Demanda Energética}

O consumo médio do campus apurado é de $652.000 \mathrm{Kwh} / \mathrm{mês}$. Este valor já considera o consumo de ponta e fora de ponta. No caso da CPFL, a tarifa de ponta é aplicada entre 18h. às $21 \mathrm{~h}$. A Figura 2 tem como base a conta de energia elétrica do mês de abril de 2017.0 consumo fora de ponta é todo o consumo do campus que é realizado fora do horário de ponta.

Figura 2 - Demanda energética do campus dos últimos 12 meses (Abril/2017) em mil.

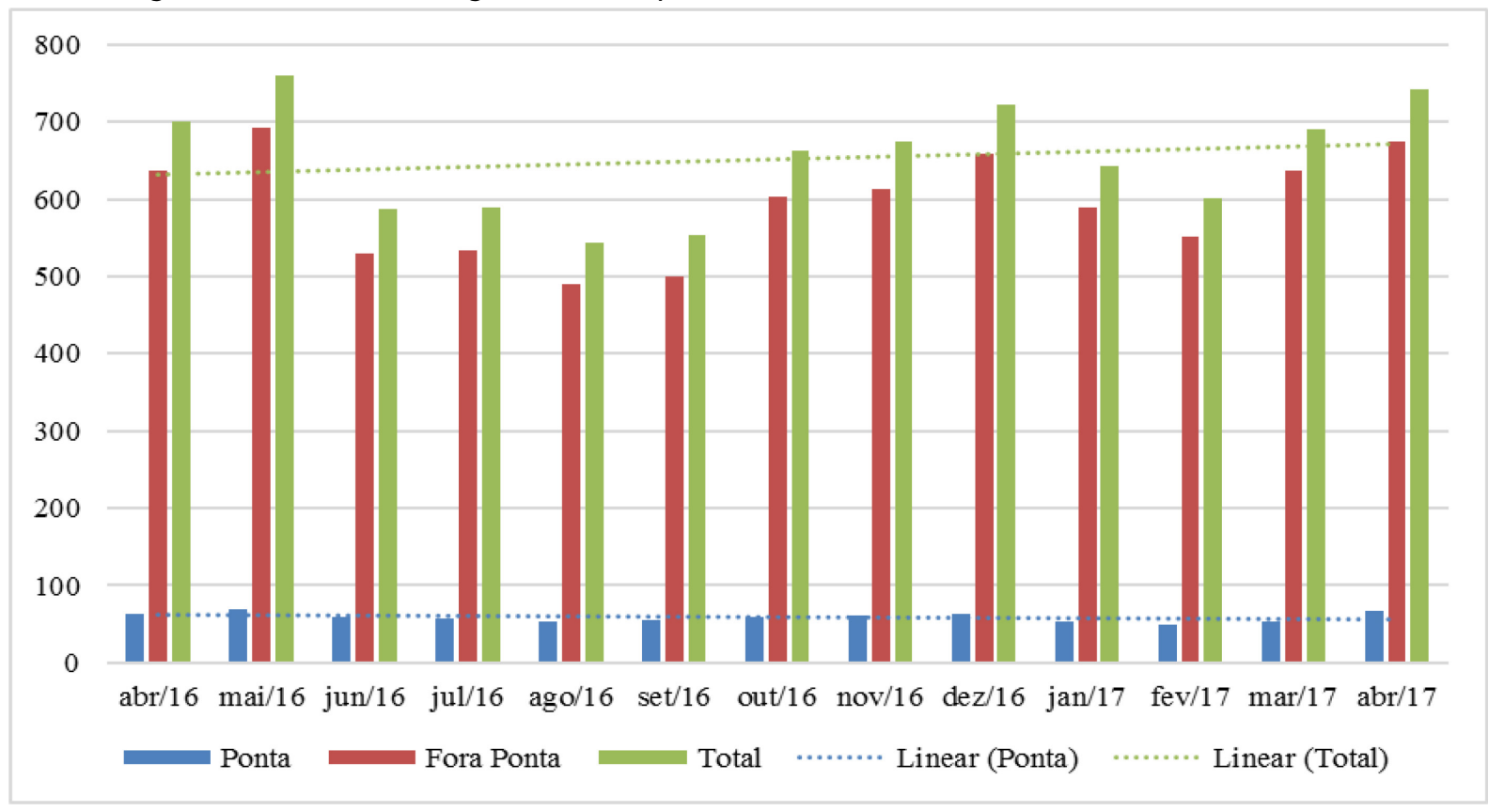

Fonte: elaboração própria (2017).

De acordo com a Lei de Diretrizes Orçamentárias de 2016, o governo estadual deve repassar no mínimo 9,57\% do total arrecadado pelo Imposto de Circulação de Mercadorias e Serviços para a UNESP, Universidade de São Paulo - USP e Universidade Estadual de Campinas - UNICAMP realizarem suas atividades (Figura 3). Deste modo, o repasse às universidades estaduais de São Paulo estão intimamente ligadas a arrecadação do estado.

A comparação dos últimos dois Gráficos revela um problema que pode, em pouco tempo, se tornar crônico. A demanda energética da faculdade avança mês a mês enquanto os repasses realizados não alcançam a meta, mesmo com a diminuição do projetado para o ano de 2017. Com isso, torna-se questão de tempo a situação em que os repasses não conseguirão honrar todos os compromissos de funcionários, pesquisas e manutenção. Isto mostra que o campus possui dois caminhos: aumentar os repasses ou diminuir sua conta de energia.

Aumentar os repasses não é um caminho possível para as universidades, tendo em vista que a crise econômica no país prejudica o consumo e este é fator-chave para a arrecadação do ICMS. Assim, o projeto de diminuição da conta de energia do campus vem de encontro à busca de formas de viabilização de produção energética de forma sustentável dentro da faculdade. 
Figura 3 - Repasses do Governo Estadual à UNESP (Projetado x Realizado)*

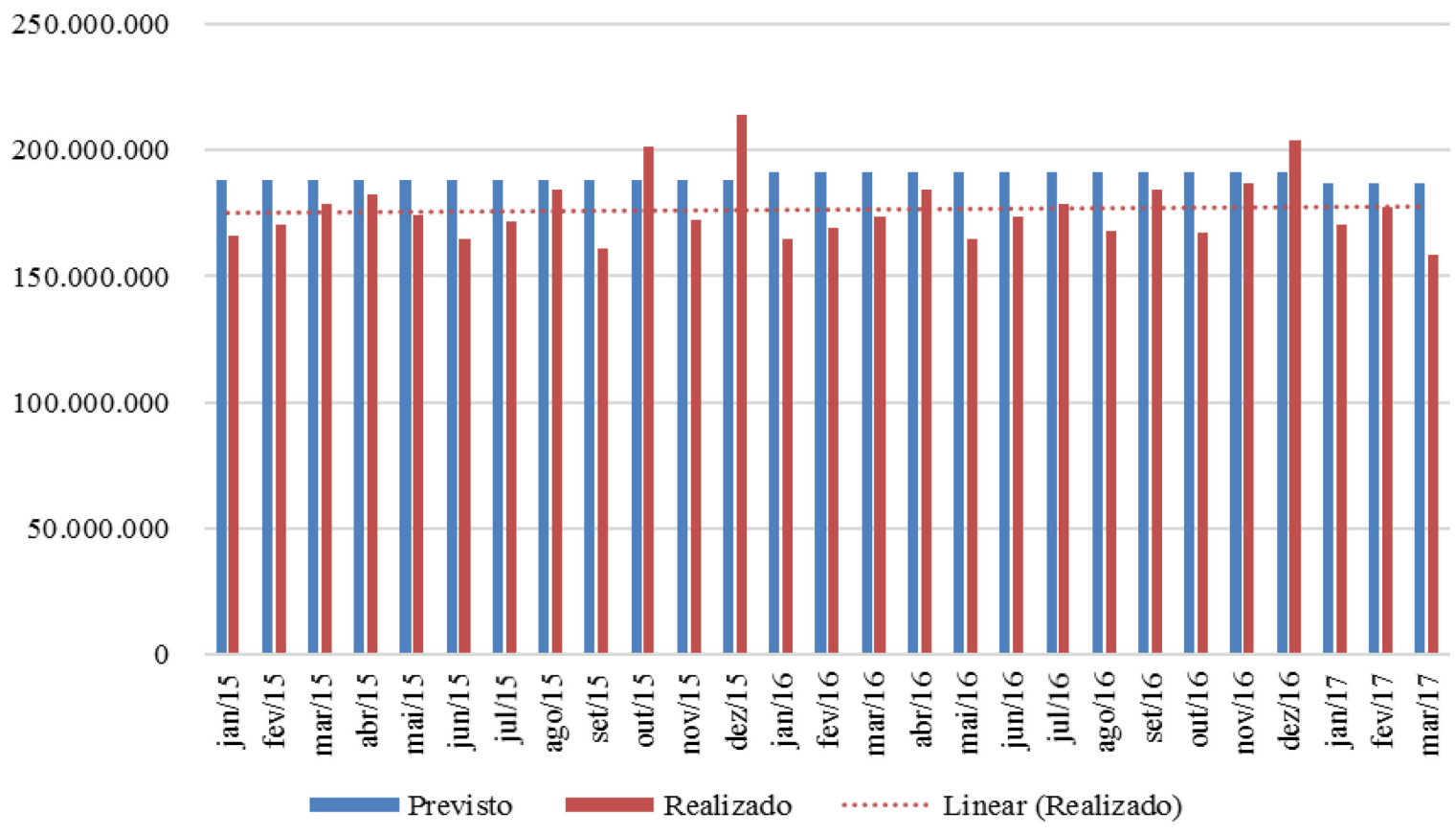

*com base nas informações públicas divulgadas pela Secretaria da Fazenda do Governo do Estado de São Paulo.

Fonte: elaboração própria (2017).

Um dos fatores limitantes para geração de energia através do sistema fotovoltaico é o nível de irradiação solar. Deste modo, inseriu-se a longitude e latitude da localização do campus da FCAV no site do SWERA (Solar and Wind Energy Resource Assessment) para aferição da irradiação. Jaboticabal, entre as regiões de Ribeirão Preto e Catanduva, possui alto índice de irradiação e esta barreira não é empecílho neste projeto. Para que se possa aproveitar ao máximo a irradiação é necessário que os módulos estejam alinhados ao Norte.

A segunda barreira informada é a utilização de espaço pelos módulos. Isto se deve ao fato dos módulo estarem dispostos na horizontal e sua área de captação deve estar exposta ao sol. O campus da FCAV possui 829 hectares e assim o espaço para a instalação do sistema não seria fator limitante. A empresa contratada realizará a forma pela qual os módulos serão instalados no chão, já que é de interesse de pesquisas da área agronômica sobre meios de produção que podem ser viabilizados embaixo do sistema.

A demanda média da FCAV, de $652.000 \mathrm{Kwh}$, excede o máximo de capacidade de uma minigeração prevista na Resolução Normativa 687, de 24 de novembro de 2015. A partir de tal demanda o sistema é considerado "usina fotovoltaica" e deve realizar diversas intervenções no local (licença ambiental), normativas (tributação) e aspectos técnicos (inserção de energia na rede de transmissão).

Sendo assim, o presente trabalho visa utilizar o modelo de minigeração de energia elétrica, de acordo com as normas da Agência Nacional de Energia Elétrica (ANEEL), para a redução das contas de energia elétrica na universidade. O modelo de usina, acima de 5MW, não será considerado por conta das diversas adequações que devem ser realizadas e tendo em vista que um projeto de $5 \mathrm{MW}$ atende a quase $100 \%$ da demanda do campus atual.

\subsection{Projeto de Investimento}

Para analisar a viabilidade do investimento, procedeu-se inicialmente com a análise de investimento - independente da sua forma de financiamento, e na sequência, estrutura-se o project finance que possa viabilizar a implantação do investimento. 


\subsubsection{Descrição dos Investimentos e Premissas do Fluxo de Caixa}

Um sistema de 5W é capaz de produzir aproximadamente $623.000 \mathrm{kWh} / \mathrm{mês}$ de acordo com as condições de irradiação do local.

A proposta comercial aceita, tendo em vista a necessidade futura de um estudo técnico aprofundado sobre o terreno, angulatura, material utilizado, estruturas físicas e preço do dólar (os principais componentes são importados) é uma estimativa que apresenta uma variação de preço. De acordo com a empresa contatada um sistema de $5 \mathrm{MW}$ teria um valor entre $\mathrm{R} \$ 24.500 .000,00$ e $\mathrm{R} \$ 25.000 .000,00$. Por razões conservadoras, a análise tomou como valor o limite máximo informado em R\$ 25 milhões. Para o sistema utilizou-se 19.206 módulos fotovoltaicos de 260 Watts de potência.

O sistema ocupará uma área total de aproximadamente $39.950 \mathrm{~m}^{2}$ ou 3,99 ha. A estrutura geralmente utilizada é a base de concreto com a sustentação em alumínio, criando um espaço de 1 a 1,5m do solo. Este fator, entretanto, será considerado como estimativa tendo em vista que a FCAV possui projetos para estudos sobre culturas a serem realizadas embaixo dos módulos solares. Segundo a empresa, o sistema não necessita de manutençao de funcionamento já que opera normalmente durante todo o tempo de vida.

O sistema possui uma perda anual de $0,8 \%$ de sua capacidade de geração. Além da perda de desgaste natural, o sistema fotovoltaico ainda possui uma perda de eficiência natural decorrente do próprio processo de geração de energia. Assim, a empresa informou que tal sistema possui perda de $18 \%$ da geração de energia por conta da transmissão através dos cabos elétricos. Considerou-se tal afirmação para a geração do fluxo de caixa. Considerou-se no fluxo de caixa tal perda anual durante todos os 25 anos de vida útil do projeto.

\subsubsection{Premissa Receita}

As receitas geradas pelo sistema serão, no caso da empresa investidora, o quanto a universidade pagará pelo $\mathrm{kWh}$. De acordo com a conta de energia da CPFL a FCAV possui uma tarifa de ponta no valor de R\$ 1,03844992 e fora ponta no valor de R\$ 0,3339777. Para projeção inicial da viabilidade econômica será utilizada a tarifa atual, de modo que o processo, para contratação do investimento poderá ser feito pelo menor valor de tarifa, sendo assim, uma função do VPL é determinada para melhor estimar os ganhos à universidade.

Tendo em vista a proposta do fluxo de caixa anual ( 12 meses vezes $623.000 \mathrm{kWh} / \mathrm{mês}$ ) considerou-se que o sistema gera, anualmente, $7.476 .000 \mathrm{Kwh} / \mathrm{ano}$. Deste modo, os cálculos utilizados para a averiguação da receita foram com base na geração anual destacada. O consumo fora ponta representa $90,2 \%$ e ponta $9,8 \%$. Levou-se esta informação em consideração na medida em que os valores de tarifa de ponta são maiores do que fora ponta.

\subsubsection{Premissa Reajustes da Tarifa}

Os reajustes de tarifa energética acontecem anualmente e são regulamentadas pela ANEEL. Para a definição de uma taxa pela qual será utilizada para reajustar as tarifas no fluxo de caixa utilizou-se os dados dos últimos cinco anos de acordo com os dados da ANEEL (2017). As tarifas e seus respectivos anos: 2012 (5\%); 2013 (-13\%); 2014 (12\%); 2015 (16\%); 2016 (13\%).

Utilizando a média dos últimos cinco anos é possível observar um aumento de 6,6\% nas tarifas das concessionárias. Ressalta-se que o ano de 2013 foi atípico nos reajustes, pois o então governo da presidente Dilma Rousseff decidiu por reduzir os custos da energia no país em busca de incentivar o consumo energético e estimular a indústria. Como o valor médio ficou $0,1 \%$ acima do teto da inflação e o valor da energia é um dos principais itens da taxa de inflação, admite-se para o fluxo de caixa que os gastos e fontes de receita terão os valores acompanhados pela inflação. Assim, todos os valores e taxa de desconto serão tomadas com base na taxa real, isto é, a taxa nominal deflacionada. 


\subsubsection{Premissa Impostos}

O CONFAZ (Conselho Nacional de Política Fazendária) instituiu em 2015, no Convênio 16/2015, que a geração de energia da forma "distribuída", ou seja, conectada à rede, é isenta de tributação estadual (ICMS). Deste modo, no momento em que o sistema da universidade estiver produzindo menos, no caso do inverno, o campus utilizará dos créditos energéticos da inserção de energia na rede quando houve excedente de produção.

Entretanto, quando os créditos se esgotarem e a universidade consumir da rede, energia a mais, este volume utilizado vai estar sujeito à tributação. Porém, a análise deste trabalho visa mostrar a forma como a SPE gerará suas receitas e assim ficará isenta de tributação sobre consumo. O imposto de renda não sofre alterações e é cobrado normalmente.

Adotar-se-á o lucro presumido pelo benefício fiscal compreendido por este modelo, na medida em que a SPE é permitida a usá-lo de acordo com a Lei 11.079/2004. Deste modo, o cálculo do Imposto de Renda e da Contribuição Social do Lucro Líquido será feito conforme as alíquotas demonstradas no modelo apresentado.

As contribuições de PIS/PASEP continuarão sob a responsabilidade da UNESP, tendo em vista que a autarquia é a consumidora da energia transmitida pela CPFL. Como o sistema utiliza o método de compensação energético, o mês em que se gerar mais do que o consumo não será cobrado tais contribuições da universidade.

\subsubsection{Premissas Depreciação, Desmobilização e Manutenção - Monitoramento}

O projeto será depreciado em parcela iguais durante os 25 anos de vida útil do mesmo. A depreciação está relacionada com todos os itens do sistema, ou seja, os módulos fotovoltaicos, os inversores de tensão, estruturas metálicas, fiação elétrica e a sustentação de solo.

Os gastos com a desmobilização do projeto referem-se aos valores gastos com a retirada da estrutura do sistema ao término dos 25 anos do projeto.

A empresa escolhida informou que possui um modelo de prestação de serviços no qual está incluso o monitoramento constante do sistema fotovoltaico. Como tal sistema não exige manutenção (apenas em caso de eventos extraordinários, como uma queda de árvore sobre os módulos) esta é feita pela própria empresa e já está incluso no preço inicial estimado.

\subsection{Estimativa Taxa de Desconto}

A taxa de desconto do empreendimento será realizada através do WACC, tendo em vista que este é o custo do capital empregado na análise do retorno do investimento. Utilizou-se o modelo Capital Assets Pricing Modelling - CAPM para identificar o custo de capital próprio (ASSAF NETO, 2012).

$O$ ativo livre de risco para o mês de realização deste estudo estava em 10,25\%. Para o cálculo do beta foi utilizado o valor deste referente à empresa CPFL Energia Renovável $(0,06)$, listada na B3, pois reflete com maior proximidade o beta do projeto de energia renovável. Como prêmio de mercado utilizou-se $6 \%$ a.a. Ressalta-se que a pesquisa está embasada em valores reais, sendo necessário deflacionar a taxa com a inflação (Utilizou-se 4,5\%, centro da meta do BACEN, como balizador). O CAPM assume tal forma:

$$
\begin{aligned}
& R_{i}=R_{f}+\beta\left(R_{m}-R_{f}\right) \\
& R_{i}=10,25+0,06(6,00) \\
& R_{i}=10,61 \% \\
& R_{i} \text { Deflacionado }=(1+0,1061) /(1+0,045)-1 \\
& R_{i} \text { Deflacionado }=5,85 \%
\end{aligned}
$$


O valor de 10,61\% é o retorno esperado pelos acionistas e investidores da empresa ou projeto por terem realizado aportes de capital em detrimento de outro projeto. Um dos limitadores de execuções de projeto no Brasil é a taxa Selic, visto que quando a taxa sobe, inviabiliza projetos.

O custo da dívida de terceiros $(\mathrm{Kd})$ é o valor dos juros dos empréstimos captados no mercado. Tendo em vista o prazo do projeto (25 anos), a única fonte de recurso disponível no mercado são os financiamentos via o Banco Nacional de Desenvolvimento Econômico e Social (BNDES). Para tal projeto utilizou-se as taxas de empresas grandes de setores prioritários, pois estes setores são incentivados por serem de investimento em geração de energia renovável (entre outros). Deste modo, considera-se a TJLP de 7\% ao ano, taxa BNDES de $2,1 \%$ ao ano e a taxa de intermediação da instituição financeira. Esta taxa reflete, segundo o BNDES, o risco sistêmico das instituições financeiras e possui valor entre $2 \%$ e $6 \%$ ao ano (com média de $4 \%$ ).

$$
\begin{aligned}
& K_{d}=F(1-I R) \\
& K_{d}=13,1 \%(1-0,34) \\
& K_{d}=8,646 \%
\end{aligned}
$$

Através dos valores apurados do custo de capital próprio e de terceiros é possível delimitar o WACC. O BNDES possui um limite de captação para tal forma de investimento de até $80 \%$ de 20 milhões de reais. Considerou-se, portanto, que 9 milhões de reais devem ser de capital próprio da empresa ganhadora da licitação, representando $36 \%$ de capital próprio. O cálculo se mostra da seguinte forma:

$$
\begin{aligned}
& W A C C=K_{e} x\left(\frac{E}{D+E}\right)+K_{d} x\left(\frac{D}{D+E}\right) \\
& W A C C=5,85 \times\left(\frac{9}{16+9}\right)+8,646 \times\left(\frac{16}{16+9}\right) \\
& W A C C=7,6394 \% .
\end{aligned}
$$

\subsection{Análise da Viabilidade Econômica (VPL, TIR, Payback)}

Foram realizados 6 fluxos de caixa referentes ao project finance do sistema fotovoltaico na UNESP, para analisar a viabilidade econômica do projeto, ou seja, a capacidade de gerar valor e retorno para os investidores. Os fluxos foram montados e acordo com a tarifa anual e os deságios de 5, 10, 15, 20, 30 e 39,9\% na tarifa de energia elétrica, seguindo a Tabela 1.

\begin{tabular}{|c|c|c|c|c|c|c|c|c|c|c|c|c|c|}
\hline Variável/anos & 0 & 1 & 2 & 3 & 4 & 5 & 6 & 7 & 8 & 9 & 10 & 11 & 12 \\
\hline (+) Receita & & 2,71 & 2,52 & 2,67 & 2,82 & 2,98 & 3,16 & 3,34 & 3,53 & 3,73 & 3,95 & 4,17 & 4,41 \\
\hline \multicolumn{14}{|l|}{ (-) Deduções } \\
\hline (=) Receita Líquida & & 2,71 & 2,52 & 2,67 & 2,82 & 2,98 & 3,16 & 3,34 & 3,53 & 3,73 & 3,95 & 4,17 & 4,41 \\
\hline \multicolumn{14}{|l|}{ (-) Custos } \\
\hline \multicolumn{14}{|l|}{ (-) Despesas } \\
\hline (-) Depreciação & & 1,00 & 1,00 & 1,00 & 1,00 & 1,00 & 1,00 & 1,00 & 1,00 & 1,00 & 1,00 & 1,00 & 1,00 \\
\hline (=) LAIR & & 1,71 & 1,52 & 1,67 & 1,82 & 1,98 & 2,16 & 2,34 & 2,53 & 2,73 & 2,95 & 3,17 & 3,41 \\
\hline (-) IR e CSLL & & 0,27 & 0,25 & 0,27 & 0,28 & 0,30 & 0,32 & 0,34 & 0,36 & 0,38 & 0,41 & 0,43 & 0,46 \\
\hline (=) Resultado Líquido & & 1,44 & 1,27 & 1,40 & 1,54 & 1,68 & 1,84 & 2,00 & 2,17 & 2,35 & 2,54 & 2,74 & 2,96 \\
\hline (+) Depreciação & & 1,00 & 1,00 & 1,00 & 1,00 & 1,00 & 1,00 & 1,00 & 1,00 & 1,00 & 1,00 & 1,00 & 1,00 \\
\hline (=) FC Operacional & & 2,44 & 2,27 & 2,40 & 2,54 & 2,68 & 2,84 & 3,00 & 3,17 & 3,35 & 3,54 & 3,74 & 3,96 \\
\hline
\end{tabular}

De acordo com a análise de viabilidade econômica, a partir dos fluxos de caixa descontados na Tabela 1, pode-se alcançar que, com a tarifa integral paga pela UNESP no Campus Jaboticabal, o projeto obteria VPL de $\mathrm{R} \$ 15.789 .690,64$, TIR de 12,61\% e Payback em 10 anos. Estes resultados asseguram, portanto, viabilidade econômica pelo valor positivo do VPL e TIR maior que a TMA.

Tabela 1 - Fluxo de Caixa com Tarifa Atual (Em R\$ Milhões) 


\begin{tabular}{|c|c|c|c|c|c|c|c|c|c|c|c|c|c|}
\hline (-) Investimento & 25,0 & 0,00 & 0,00 & 0,00 & 0,00 & 0,00 & 0,00 & 0,00 & 0,00 & 0,00 & 0,00 & 0,00 & 0,00 \\
\hline (=) FC Livre & $-25,0$ & 2,44 & 2,27 & 2,40 & 2,54 & 2,68 & 2,84 & 3,00 & 3,17 & 3,35 & 3,54 & 3,74 & 3,96 \\
\hline Continuação & 13 & 14 & 15 & 16 & 17 & 18 & 19 & 20 & 21 & 22 & 23 & 24 & 25 \\
\hline (+) Receita & 4,67 & 4,93 & 5,22 & 5,52 & 5,84 & 6,17 & 6,53 & 6,90 & 7,30 & 7,72 & 8,16 & 8,63 & 9,12 \\
\hline (-) Deduções & & & & & & & & & & & & & \\
\hline (=) Receita Líquida & 4,67 & 4,93 & 5,22 & 5,52 & 5,84 & 6,17 & 6,53 & 6,90 & 7,30 & 7,72 & 8,16 & 8,63 & 9,12 \\
\hline
\end{tabular}

\begin{tabular}{llllllllllllll} 
(-) Depreciação & 1,00 & 1,00 & 1,00 & 1,00 & 1,00 & 1,00 & 1,00 & 1,00 & 1,00 & 1,00 & 1,00 & 1,00 & 1,00 \\
(=) LAIR & 3,67 & 3,93 & 4,22 & 4,52 & 4,84 & 5,17 & 5,53 & 5,90 & 6,30 & 6,72 & 7,16 & 7,63 & 8,12 \\
\hline
\end{tabular}

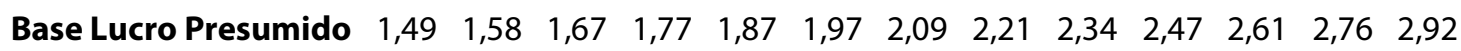

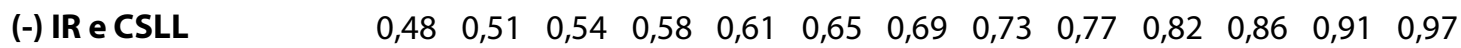

$\begin{array}{llllllllllllll}\text { (=) Resultado Líquido } & 3,18 & 3,42 & 3,67 & 3,94 & 4,22 & 4,52 & 4,84 & 5,17 & 5,53 & 5,90 & 6,30 & 6,71 & 7,16\end{array}$

(+) Depreciação $\quad \begin{array}{llllllllllllll}1,00 & 1,00 & 1,00 & 1,00 & 1,00 & 1,00 & 1,00 & 1,00 & 1,00 & 1,00 & 1,00 & 1,00 & 1,00\end{array}$

(=) FC Operacional $\quad$\begin{tabular}{llllllllllllll}
4,18 & 4,42 & 4,67 & 4,94 & 5,22 & 5,52 & 5,84 & 6,17 & 6,53 & 6,90 & 7,30 & 7,71 & 8,16 \\
\hline
\end{tabular}

\begin{tabular}{llllllllllllll}
\hline (-) Investimento & 0,00 & 0,00 & 0,00 & 0,00 & 0,00 & 0,00 & 0,00 & 0,00 & 0,00 & 0,00 & 0,00 & 0,00 & 0,00
\end{tabular}

\begin{tabular}{lllllllllllllll} 
(=) FC Livre & 4,18 & 4,42 & 4,67 & 4,94 & 5,22 & 5,52 & 5,84 & 6,17 & 6,53 & 6,90 & 7,30 & 7,71 & 8,16 \\
\hline
\end{tabular}
Fonte: elaboração própria, a partir dos dados da pesquisa (2017).

Ressalta-se, ainda, que o projeto nestas condições apresenta IL de 0,6316, o que demonstra uma lucratividade de $63,16 \%$ frente o valor inicial do investimento. Estes dados mostram que o projeto tem potencial para criar valor durante o tempo e apresenta retorno ao investidor.

A Tabela 2 traz uma análise de sensibilidade do perfil deste Fluxo de Caixa Descontado considerando a possibilidade da parceria público e privada o limite de deságio aceitável para o pagamento da tarifa de energia.

Tabela 2 - VPL, TIR, TMA, IL e Economia total do sistema a partir do deságio na tarifa de energia (Valores em R\$ Mil)

\begin{tabular}{|c|c|c|c|c|c|c|c|}
\hline $\begin{array}{l}\text { Indicadores / } \\
\text { deságio }\end{array}$ & Integral (0\%) & $5 \%$ & $10 \%$ & $15 \%$ & $20 \%$ & $30 \%$ & $39,90 \%$ \\
\hline VPL & $16.041,26$ & $13.763,42$ & $11.737,15$ & $9.710,88$ & $7.684,61$ & $3.632,07$ & 25,31 \\
\hline TIR & $12,72 \%$ & $12,03 \%$ & $11,44 \%$ & $10,83 \%$ & $10,20 \%$ & $8,90 \%$ & $7,65 \%$ \\
\hline TMA & $7,64 \%$ & $7,64 \%$ & $7,64 \%$ & $7,64 \%$ & $7,64 \%$ & $7,64 \%$ & $7,64 \%$ \\
\hline IL & 0,64 & 0,55 & 0,47 & 0,39 & 0,31 & 0,15 & 0,00 \\
\hline Econ. & 0,00 & $10.232,19$ & $20.464,38$ & $30.696,56$ & $40.928,75$ & $61.393,13$ & $79.606,42$ \\
\hline
\end{tabular}

Fonte: elaboração própria, a partir dos dados da pesquisa (2017).

Observa-se que o potencial econômico do empreendimento diminui à medida que os deságios a serem pagos pela FCAV à SPE aumentam, chegando a quase zero na taxa 39,9\%, sendo esta, portanto, uma taxa limite à viabilidade econômica do projeto.

Verifica-se que para a FCAV qualquer deságio na tarifa atual criará valor, pois a universidade não precisará realizar o investimento e terceirizar toda a gestão da SPE para a parceria público-privada. Os resultados econômicos para a FCAV em todo o perfil do Fluxo de Caixa Descontado podem ser observados na Figura 4. 
Figura 4 - VPL e Economia total de energia em função dos deságios

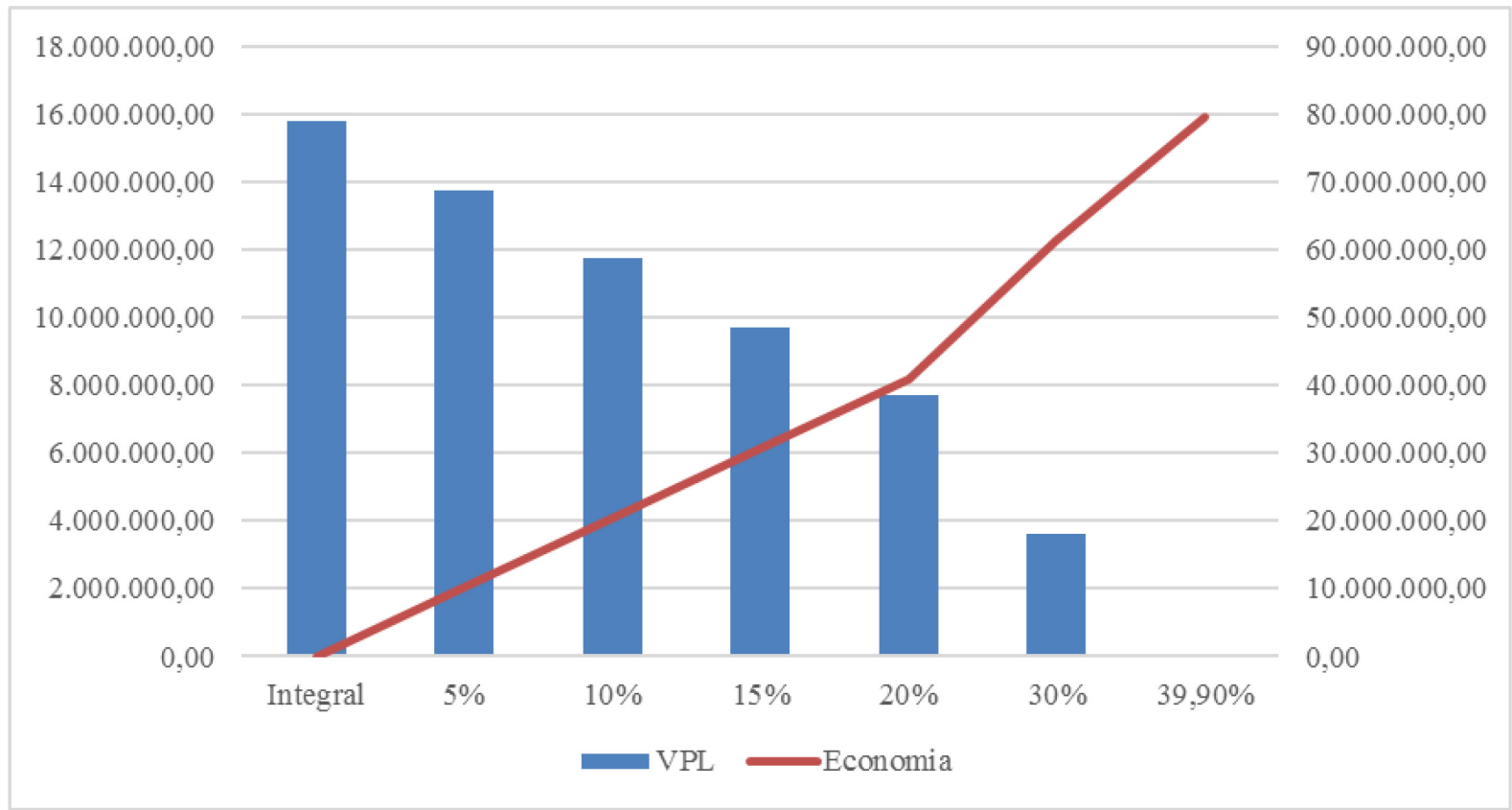

Fonte: elaboração própria, a partir dos dados da pesquisa (2017).

Para a SPE é interessante que a tarifa se mantenha a mesma, com os benefícios para o campus relacionados à pesquisa e área de inovação. Deste modo, a SPE teria um VPL positivo e uma TIR de 12,61\% que se mostra bem acima da TMA (7,64\%). Este modelo seria o ideal para os investidores, pois estes buscam maximizar seus retornos na medida em que escolhem os projetos que possuam maior VPL (ASSAF NETO, 2012).

No modelo de pagamento de tarifa integral o campus, apesar da manutenção do pagamento integral da energia elétrica, possuirá uma usina fotovoltaica com viés pioneiro (considerando que atualmente não há universidades com tal projeto no Brasil) e material para pesquisa. Como todo o sistema está sob a responsabilidade da SPE, o campus não terá gasto algum para instalação ou manutenção, apenas fará a cessão do espaço à SPE para a instalação da usina.

Entretanto, há ainda outras opções que podem ser viabilizadas para que tanto os investidores quanto a FCAV possam viabilizar seus retornos. Apesar de possuírem VPLs menores, os deságios entre $5 \%$ e $30 \%$ se mostram interessantes em termos de retorno para a SPE. Para a universidade tais deságios são ainda mais atrativos, na medida em que serão desembolsados menores valores para o pagamento de energia e gerará uma economia considerável para o campus.

O deságio de 39,9\% sobre o valor da tarifa paga atualmente é o mais vantajoso para a FCAV, pois a economia total dentro da vida útil do projeto seria de $\mathrm{R} \$ 204.643 .765$. Este modelo apresenta um VPL de $\mathrm{R} \$ 25.308,72$, TIR de 7,65\%, Payback de 14 anos e IL igual a zero. Isso demonstra que esse modelo de deságio está no limite, pois a TIR é próxima à TMA de 7,64\%.

Este modelo, apesar de aliviar as contas energéticas da FCAV, pode não ser atrativos para os investidores. Isso porque a criação de uma SPE e a consecução de uma PPP possui trâmites burocráticos e dispendiosos, o que poderia diminuir o interesse daqueles. Nota-se que o potencial de criação de retorno é quase nulo, ou seja, o valor investido será retomado nos anos do sistema, apenas corrigido pela TIR. Entretanto, tal projeto possui caráter pioneiro e visionário tendo em vista que não há campus no Brasil que são sustentados por tal modelo de geração.

Portanto, o sistema proposto até o limite de deságio de 39,9\% sobre a tarifa apresenta-se com viabilidade econômica. 


\subsection{Project Finance}

O project finance, como forma de engenharia financeira, possui uma estrutura voltada a uma realização de fluxo de caixa previsível ou estipulado de acordo com os ativos do projeto e buscando mitigar os riscos (BONOMI; MALVESSI, 2008). Na PPP, entretanto, pode não haver qualquer fluxo de caixa, como no caso dos presídios ou não ser de possível previsão.

Ressalta-se que na PPP o interesse público impera sobre o interesse das partes privadas e desse modo os riscos envolvidos, além dos identificados de mercado, são por vezes relacionados às questões políticas do país. Os parceiros privados devem assumir os riscos e as responsabilidades do projeto na medida definida pelo governo, independentemente da situação do mercado.

Para iniciar o project finance é necessário que haja primeiramente a licitação da viabilidade técnica do empreendimento. Após a licitação há a formação da Sociedade de Propósito Específico (SPE) para que se possa realizar as operações da obra. A SPE receberá recursos dos investidores privados (empresa ganhadora) e do governo do estado (Figura 5).

Cria-se uma conta corrente para que se possa centralizar e direcionar os recursos provenientes do projeto. Pode ser inserido, no caso, um agente fiduciário (trustee) que ofereça aos credores do empreendimento a segurança necessária para a realização dos aportes. Esta conta corrente deverá ser utilizada para os pagamentos corriqueiros, como salários e materiais e, principalmente o abatimento das parcelas do financiamento perante o BNDES.

Os investidores privados serão as pessoas físicas ou empresas que desejarem investir na aplicação do sistema na faculdade e assim obterem retorno com o projeto. Não há limitação em relação a quantidade de sócios, entretanto o valor captado de recursos não deverá ser superior aos nove milhões de reais já definidos anteriormente. Os investidores aplicarão diretamente na SPE.

A FCAV realizará todo o trâmite de licitação e irá ceder o espaço necessário para a instalação do sistema no campus. Neste estudo o governo não entrará com recursos de capital para a realização da obra, porém terá participação no empreendimento, pois disponibilizará a área de aproximadamente 4 ha para instalação das placas. Haverá, entretanto, a fiscalização do governo sobre a destinação dos recursos aplicados bem como a consecução da obra.

Figura 5 - Modelo de SPE para o sistema fotovoltaico da FCAV/FCAV

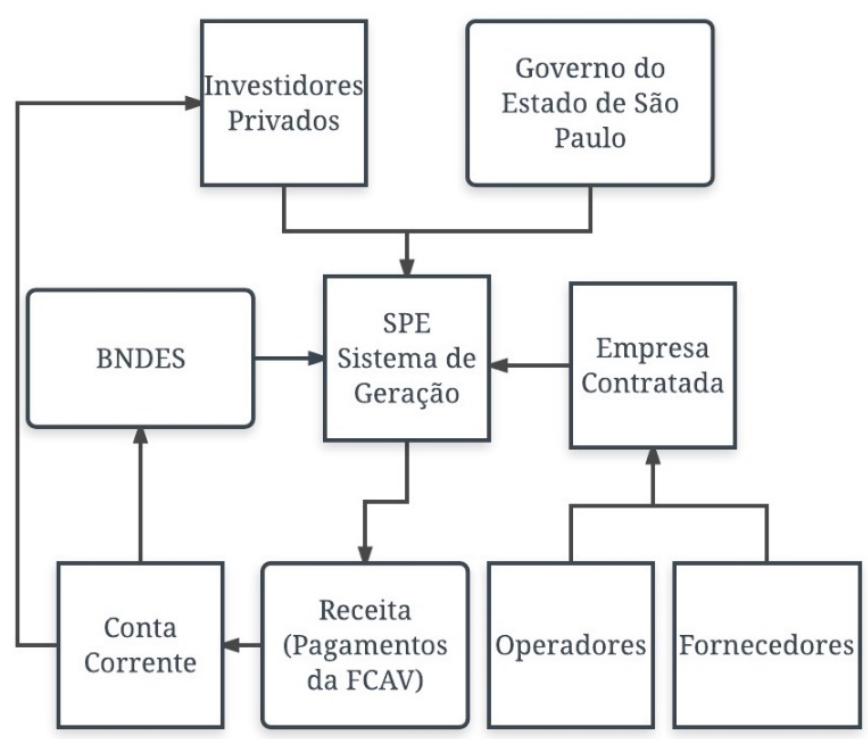

Fonte: elaboração própria (2017). 
A SPE será formada a fim de prestar o serviço contratado e assim realizar o empreendimento licitado. No presente estudo, a SPE é a titular dos direitos e obrigações decorrentes do contrato de execução da obra. A SPE poderá contratar, caso necessário, uma seguradora para que o governo atue firmemente na fiscalização de obra e assim dê segurança de realização aos credores.

A empresa contratada para realizar o serviço será uma atuante do setor solar e que possua experiência na construção de sistemas maiores do que microgeração. Esta empresa deverá realizar a parte de estruturação de solo e deverá estar contato com os responsáveis e especialistas do campus sobre as necessidades de elevação ou não módulos em razão de posteriores estudos agronômicos sobre plantações e solo.

Os operadores e fornecedores ficarão a cargo da empresa contratante, tendo em vista que o processo licitatório concluído já apresenta os valores reais de orçamento da obra. Desse modo, o governo atuará na fiscalização caso os materiais utilizados não tenham sido os mesmos contratados na licitação, seja por qualidade, tamanho, especificações ou outra informação que possa comprometer a correta e limpa geração de energia.

A receita dos pagamentos (fluxo de capital) será realizada para uma conta corrente em uma instituição financeira ou trustee de confiança dos credores. Esta conta será utilizada para a realização das despesas ordinárias, como o pagamento de salários e fornecedores, bem como o pagamento de juros e amortização dos empréstimos realizados junto ao BNDES. Esta conta corrente remunera, também, os investidores privados.

O BNDES será a fonte de financiamento do projeto e a aplicação de seus recursos será diretamente na SPE para que então seja repassado aos fornecedores. Ressalta-se que o agente financeiro possui o direito de obter a qualquer momento informações sobre indicadores do projeto, bem como o atingimento ou não das metas estipuladas em contrato.

\subsection{Viabilidade Financeira do Projeto com a SPE}

Para o cálculo da viabilidade financeira, tendo em vista que o sistema já é viável economicamente, é necessário verificar as despesas com juros e a amortização da dívida.

A amortização será realizada através das receitas oriundas da geração de energia do sistema, pagas sob forma de tarifa pela FCAV. Cabe então entender se estas receitas são capazes de gerar caixa suficiente para a manutenção do sistema e o pagamento dos débitos financeiros. No fluxo de caixa terá a nomenclatura de "Despesas Financeiras" no qual incluirá o pagamento dos juros e as amortizações.

O BNDES utiliza tradicionalmente o sistema SAC (Sistema de Amortização Constante), no qual se adicionará à dívida os juros representativos do montante investido na implantação, considerando juros da poupança, inflação e taxa Selic respectivamente.

O BNDES permite que haja uma carência de 36 meses para o início do pagamento da primeira parcela. O prazo total do financiamento é de 240 meses o que equivale a 20 anos do projeto. Ressalta-se que o banco permite o financiamento de até $80 \%$ de um projeto de 20 milhões de reais. Desse modo, para a simulação do financiamento foi utilizado como recursos de terceiros o valor de 16 milhões de reais (já considerados anteriormente no cálculo do WACC).

O projeto, segundo a Tabela 3, tem viabilidade financeira com a tarifa integral, ou seja, a forma de financiamento proposta pelo BNDES consegue apresentar fluxos de caixa positivos durante a vida útil. Esta modalidade de financiamento, ressalta-se, foi utilizada pois a SPE tem o objetivo de construir uma usina fotovoltaica para atender ao campus de uma universidade, atendendo assim o requisito de "inovação" solicitada pelo banco. 
Tabela 3 - Fluxo de Caixa de Tarifa Integral com Despesas de Juros e Amortização (Em R\$ Milhões)

\begin{tabular}{|c|c|c|c|c|c|c|c|c|c|c|c|c|c|}
\hline Variável/anos & 0 & 1 & 2 & 3 & 4 & 5 & 6 & 7 & 8 & 9 & 10 & 11 & 12 \\
\hline (+) Receita & & 2,71 & 2,52 & 2,67 & 2,82 & 2,98 & 3,16 & 3,34 & 3,53 & 3,73 & 3,95 & 4,17 & 4,41 \\
\hline \multicolumn{14}{|l|}{ (-) Deduções } \\
\hline (=) Receita Líquida & & 2,71 & 2,52 & 2,67 & 2,82 & 2,98 & 3,16 & 3,34 & 3,53 & 3,73 & 3,95 & 4,17 & 4,41 \\
\hline \multicolumn{14}{|l|}{ (-) Custos } \\
\hline (-) Despesas & & 1,36 & 1,39 & 1,43 & 2,50 & 2,50 & 2,51 & 2,52 & 2,54 & 2,55 & 2,58 & 2,61 & 2,64 \\
\hline (-) Depreciação & & 1,00 & 1,00 & 1,00 & 1,00 & 1,00 & 1,00 & 1,00 & 1,00 & 1,00 & 1,00 & 1,00 & 1,00 \\
\hline$(=)$ LAIR & & 0,35 & 0,13 & 0,24 & $-0,68$ & $-0,52$ & $-0,35$ & $-0,18$ & $-0,01$ & 0,18 & 0,37 & 0,56 & 0,77 \\
\hline (-) IR e CSLL & & 0,27 & 0,25 & 0,27 & 0,28 & 0,30 & 0,32 & 0,34 & 0,36 & 0,38 & 0,41 & 0,43 & 0,46 \\
\hline (=) Resultado Líquido & & 0,08 & $-0,12$ & $-0,03$ & $-0,96$ & $-0,82$ & $-0,67$ & $-0,52$ & $-0,37$ & $-0,21$ & $-0,04$ & 0,13 & 0,31 \\
\hline (+) Depreciação & & 1,00 & 1,00 & 1,00 & 1,00 & 1,00 & 1,00 & 1,00 & 1,00 & 1,00 & 1,00 & 1,00 & 1,00 \\
\hline (=) FC Operacional & & 1,08 & 0,88 & 0,97 & 0,04 & 0,18 & 0,33 & 0,48 & 0,63 & 0,79 & 0,96 & 1,13 & 1,31 \\
\hline (-) Investimento & 25,0 & 0,00 & 0,00 & 0,00 & 0,00 & 0,00 & 0,00 & 0,00 & 0,00 & 0,00 & 0,00 & 0,00 & 0,00 \\
\hline (=) FC Livre & $-25,0$ & 1,08 & 0,88 & 0,97 & 0,04 & 0,18 & 0,33 & 0,48 & 0,63 & 0,79 & 0,96 & 1,13 & 1,31 \\
\hline
\end{tabular}

\begin{tabular}{|c|c|c|c|c|c|c|c|c|c|c|c|c|c|}
\hline Continuação & 13 & 14 & 15 & 16 & 17 & 18 & 19 & 20 & 21 & 22 & 23 & 24 & 25 \\
\hline (+) Receita & 4,67 & 4,93 & 5,22 & 5,52 & 5,84 & 6,17 & 6,53 & 6,90 & 7,30 & 7,72 & 8,16 & 8,63 & 9,12 \\
\hline \multicolumn{14}{|l|}{ (-) Deduções } \\
\hline (=) Receita Líquida & 4,67 & 4,93 & 5,22 & 5,52 & 5,84 & 6,17 & 6,53 & 6,90 & 7,30 & 7,72 & 8,16 & 8,63 & 9,12 \\
\hline \multicolumn{14}{|l|}{ (-) Custos } \\
\hline (-) Despesas & 2,69 & 2,73 & 2,79 & 2,85 & 2,91 & 2,99 & 3,07 & 3,52 & & & & & \\
\hline (-) Depreciação & 1,00 & 1,00 & 1,00 & 1,00 & 1,00 & 1,00 & 1,00 & 1,00 & 1,00 & 1,00 & 1,00 & 1,00 & 1,00 \\
\hline (=) LAIR & 0,98 & 1,20 & 1,43 & 1,67 & 1,92 & 2,18 & 2,46 & 2,38 & 6,30 & 6,72 & 7,16 & 7,63 & 8,12 \\
\hline
\end{tabular}

\begin{tabular}{|c|c|c|c|c|c|c|c|c|c|c|c|c|c|}
\hline Base Lucro Presumido & 1,49 & 1,58 & 1,67 & 1,77 & 1,87 & 1,97 & 2,09 & 2,21 & 2,34 & 2,47 & 2,61 & 2,76 & 2,92 \\
\hline (-) IR e CSLL & 0,48 & 0,51 & 0,54 & 0,58 & 0,61 & 0,65 & 0,69 & 0,73 & 0,77 & 0,82 & 0,86 & 0,91 & 0,97 \\
\hline (=) Resultado Líquido & 0,50 & 0,69 & 0,89 & 1,10 & 1,31 & 1,54 & 1,77 & 1,66 & 5,53 & 5,90 & 6,30 & 6,71 & 7,16 \\
\hline (+) Depreciação & 1,00 & 1,00 & 1,00 & 1,00 & 1,00 & 1,00 & 1,00 & 1,00 & 1,00 & 1,00 & 1,00 & 1,00 & 1,00 \\
\hline (=) FC Operacional & 1,50 & 1,69 & 1,89 & 2,10 & 2,31 & 2,54 & 2,77 & 2,66 & 6,53 & 6,90 & 7,30 & 7,71 & 8,16 \\
\hline (-) Investimento & 0,00 & 0,00 & 0,00 & 0,00 & 0,00 & 0,00 & 0,00 & 0,00 & 0,00 & 0,00 & 0,00 & 0,00 & 0,00 \\
\hline (=) FC Livre & 1,50 & 1,69 & 1,89 & 2,10 & 2,31 & 2,54 & 2,77 & 2,66 & 6,53 & 6,90 & 7,30 & 7,71 & 8,16 \\
\hline
\end{tabular}

Fonte: elaboração própria, a partir dos dados da pesquisa (2017).

Alguns detalhes devem ser destacados: o BNDES prevê a carência de 36 meses para o início do pagamento da primeira amortização, sendo que nos 3 primeiros anos serão pagos apenas os juros de forma trimestral. Deste modo, é possível observar que a partir do ano 4 até o ano 8, a SPE apresente LAIR negativo e que impactam diretamente no resultado líquido.

Nota-se que no ano 4 realmente há uma queda considerável no FC livre, reduzindo o valor em comparação ao ano 3. Entretanto, com o aumento do reajuste da tarifa, e consequentemente da receita, a amortização tem cada vez menos peso e a capacidade de geração de caixa aumenta ano a ano. A partir do ano 21 não há mais despesas com juros nem amortização.

Fez-se um teste com a tarifa com deságio de $5 \%$ para verificar a viabilidade financeira da mesma. Notou-se que no ano 4 o FC livre apresenta valor negativo, ou seja, sua geração de caixa não é suficiente para 
a manutenção do sistema e das despesas financeiras. Desse modo, a partir do deságio de 5\%, já se constata que o sistema não possui viabilidade financeira.

Entretanto, tal evento pode ser corrigido caso haja readequação no WACC, inserindo no projeto mais capital próprio para que se possa diminuir as despesas financeiras. Deve-se lembrar, porém, que a inserção de mais capital próprio aumenta o WACC na medida em que o Ke apresenta uma taxa maior do que o Kd, ou seja, o investidor necessita de um retorno maior pelo risco incorrido do que o retorno esperado pela instituição financeira.

Outro modo de resolução de tal objeção é a tomada de novo financiamento para capital de giro, desta vez de curto prazo, para que se possa cobrir as despesas do período. Os empréstimos poderiam ser realizados em outra instituição financeira (O BNDES não realizaria outro aporte em um mesmo projeto) e desse modo as taxas cobradas seriam superiores ao praticado pelo banco estatal.

Considerou-se, portanto, que um capital de giro extra fosse captado na busca de analisar o potencial de viabilidade financeira. Deste modo, observou-se que com o novo aporte o projeto consegue gerar caixa suficiente para a manutenção de suas operações e consequentemente a sustentabilidade financeira dos investimentos.

Para a determinação do capital de giro extra foi considerado os valores de fluxos de caixa negativo dos períodos trazidos a valor presente. Assim torna-se possível apurar o montante necessário para cobrir o caixa em situações em que o resultado é deficitário. Há de se considerar os ganhos financeiros decorrentes das aplicações dos valores excedentes de caixa nos períodos em que há FC positivos.

Entretanto, apesar dos esforços na busca de encontrar viabilidade financeira, é necessário observar novamente a viabilidade econômica tendo em vista que o investimento fora alterado. Para o FC com deságio de $5 \%$ e $10 \%$ obteve-se os seguintes valores, respectivamente: VPL $(-2.760,94 ;-7.008,97)$ e TIR $(6,89 \% ; 5,81 \%)$.

Através do VPL e da TIR é possível analisar a incapacidade econômica do projeto (VPL negativo e TIR menor que o WACC) levando em consideração os novos aportes. Apesar de ser a forma encontrada para sanar os FC negativos esses valores fizeram com que o projeto perdesse a viabilidade econômica. Dentre todos, portanto, apenas o projeto com o pagamento integral da tarifa possui a viabilidade econômica e financeira, considerando a necessidade de financiamento junto ao BNDES. Assim, caso o(s) investidor(es) tenha(m) condições próprias de realizar o investimento, o projeto apresentará viabilidade econômica e financeira.

\section{CONCLUSÃO}

De acordo com os estudos realizados tendo em vista o ferramental da viabilidade econômicofinanceira a conclusão é de que o sistema: é economicamente e financeiramente viável. Deste modo, observando todas as premissas realizadas nesta pesquisa, o sistema é possível de ser instalado no campus através de um modelo de PPP com os detalhes mencionados nos resultados.

Para a FCAV a tarifa com deságio de 39,9\% seria a mais vantajosa, sendo que a economia gerada pelo sistema chegaria a quase 80 milhões de reais. Isto seria um fator importante para a manutenção de pesquisas e bolsas nas universidades, tendo em vista que os repasses poderiam ser utilizados de formas mais produtivas e voltadas à pesquisa e a extensão.

Para a SPE seria vantajoso que a FCAV pagasse a tarifa de modo integral no valor atual. Sabe-se que para o campus a manutenção da tarifa não impactaria nas contas e ainda obteria um sistema inovador dentro de sua área. Entretanto, há uma faixa de deságio entre $5 \%$ e $20 \%$ que se mostra interessante para os dois lados, tendo em vista a remuneração do investidor e o menor preço de tarifa para a universidade.

A viabilidade financeira do projeto é um desafio em razão dos elevados custos de financiamento do país, no entanto, ao demonstrar a viabilidade econômica é possível posicionar o projeto para investidores institucionais (fundos de pensão), incluindo internacionais, cujas taxas de oportunidades são mais competitivas que aquelas praticadas no Brasil. Não obstante, em um cenário de redução da taxa Selic, o projeto torna-se então viável e factível de ser realizado.

Apesar de ser um estudo de caso específico, entende-se que este estudo seja representativo para outras instituições e que possa motivar novos estudos nessa área quanto a estratégia de diversificação de 
fontes energéticas para universidades e outras autarquias públicas, contribuindo não somente para um ambiente mais limpo, como também para a maior eficiência no uso dos recursos financeiros do estado.

Não obstante, a utilização de PPP pode ser uma estratégia importante para viabilizar o investimento no curto e médio prazo de forma abrangente para as 295 IES públicas. Observa-se que há possibilidade de viabilizar o investimento, sem requerer o desembolso pelo estado, e ainda liberar recursos de custeio para outras atividades das IES. Ressalta-se ainda, benefícios indiretos como a possibilidade de 'dinamizar' o setor com o desenvolvimento dos fornecedores a partir da demanda o que gera além de benefícios econômicos e sociais também permitirá a consolidação desta cadeia no país e, com efeito, no longo prazo a redução dos gastos para implantação do investimento em outros empreendimentos.

A expansão desta fonte de energia para outras IES (privadas) ou mesmo escolas poderá trazer uma nova realidade para a geração de energia solar no Brasil com múltiplos benefícios para toda a sociedade. Todavia, o modelo econômico evidenciou a dificuldade em viabilizar investimentos no país com a estrutura econômica que baliza a definição da taxa básica de juros (Selic), assim, a redução de forma consistente dessa taxa poderá contribuir de forma significativa à realização de projetos de energia solar no país.

\section{REFERÊNCIAS}

AGÊNCIA NACIONAL DE ENERGIA ELÉTRICA - ANEEL. Calendário e Resultado dos Processos Tarifários de Distribuição. Disponível em: http://www.aneel.gov.br/resultado-dos-processos-tarifarios-de-distribuicao. Acesso em: 10 set. 2017.

ARAGÓN, C. S.; PAMPLONA, E.; MEDINA, V. J. R. Identificação de investimentos em eficiência energética e sua avaliação de risco. Gestão \& Produção, v. 20, n. 3, p. 525-536, 2013.

ARWU. Classificação Académica das Universidades Mundiais 2016. Disponível em: http://www.shanghairanking.com/ARWU2016.html. Acesso em: 17 set. 2017.

ASSAF NETO, A. Finanças Corporativas e Valor. São Paulo: Atlas, 2012.

PEREIRA, L. C. B. Da administração pública burocrática à gerencial. Revista do Serviço público, v. 47, n. 1, p. $1-28,1996$.

BONOMI, C. A.; MALVESSI, O. Project Finance no Brasil: Fundamentos e Estudos de Caso. 3. ed. São Paulo: Atlas, 2008.

CHEIN, F.; LEMOS, M. B.; ASSUNÇÃO, J. J. Desenvolvimento desigual: evidências para o Brasil. Revista Brasileira de Economia, v. 61, n. 3, p. 301-330, 2007.

EMPRESA DE PESQUISA ENERGÉTICA - EPE. Balanço Energético Nacional. Rio de Janeiro: Ministério de Minas e Energia, 2016.

FACULDADE DE CIÊNCIAS AGRÁRIAS E VETERINÁRIAS - FCAV. Instituição. Disponível em: http://www.fcav.unesp.br/\#!/instituicao/. Acesso em: 10 set. 2017.

FALQUETO, J. M. Z.; FARIAS, J. S. A trajetória e a funcionalidade da universidade pública brasileira. Revista Gestão Universitária na América Latina-GUAL, v. 6, n. 1, p. 22-41, 2013.

FERREIRA, A.; LEOPOLDI, M. A. A contribuição da universidade pública para a inovação e o desenvolvimento regional: a percepção de gestores e pesquisadores. Revista Gestão Universitária na América Latina-GUAL, v. 6, n. 1, p. $60-82,2013$. 
GEOTHERMAL TECHNOLOGIES OFFICE - GTO. 2016 Annual Report Geothermal Technologies Office. Disponível em: https://www.energy.gov/eere/geothermal/downloads/2016-annual-report-geothermaltechnologies-office. Acesso em: 03 dez. 2017.

GÖTZ, M. et al. Renewable Power-to-Gas: A technological and economic review. Renewable energy, v. 85, p. $1371-1390,2016$.

HOFF, D. N.; PEREIRA, C. A.; DE PAULA, L. G. N. O impacto da universidade pública no desenvolvimento regional sob a luz da literatura internacional. REDES: Revista do Desenvolvimento Regional, v. 22, n. 1, p. 510-527, 2017.

IBIAPINA NERES, J. C.; FERREIRA, M. E.; SILVA JÚNIOR, N. J. Análise socioambiental de bacia hidrográfica com usinas hidroelétricas. Mercator-Revista de Geografia da UFC, v. 11, n. 24, 2012.

INSTITUTO NACIONAL DE ESTUDOS E PESQUISAS EDUCACIONAIS ANÍSIO TEIXEIRA - INEP. Sinopses Estatísticas da Educação Superior - Graduação. Brasília - DF. 2015. Disponível em:

http://portal.inep.gov.br/web/guest/sinopsesestatisticas-da educacao-superior. Acesso em: 02 dez. 2017.

MEYER, A. A Case Study: Solar Panels at Boston College. Environmental Studies Senior Seminar. Boston: 2014.

MOREIRA, A. R. B.; DAVID, P. A.; ROCHA, K. Regulação do preço da energia elétrica e viabilidade do investimento em geração no Brasil. IPEA - Texto para discussão No978, p. 1-21, 2003.

NERES, I. J. C., FERREIRA, M. E., SILVA JR., N. J. Análise socioambiental de bacia hidrográfica com usinas hidroelétricas. Mercator-Revista de Geografia da UFC, v. 11, n. 24, 2012.

OLIVEIRA JR., A. A universidade como polo de desenvolvimento local-regional. Caderno de Geografia, v. 24, n. 1, p. 1-12, 2014.

PASCUCl, L. et al. Managerialism na gestão universitária: implicações do planejamento estratégico segundo a percepção de gestores de uma universidade pública. Revista Gestão Universitária na América LatinaGUAL, v. 9, n. 1, p. 37-59, 2016.

PENIN, S. T. S. A formação de professores e a responsabilidade das universidades. Estudos avançados, v. 15, n. 42 , p. 317-332, 2001

PEREIRA, R. S.; DOS SANTOS, D. A. Administrando a escassez nas instituições federais de ensino superior. Estudos em Avaliação Educacional, v. 18, n. 36, p. 139-166, 2007.

RIGHETTI, S. Crise nas universidades. Ciência e Cultura, v. 69, n. 2, p. 6-8, 2017.

SAMPAIO, R. M.; LANIADO, R. N. Uma experiência de mudança da gestão universitária: o percurso ambivalente entre proposições e realizações. Revista de Administração Pública, v. 43, n. 1, p. 151-174. 2009.

SILVA, P. M. et al. Planejamento orçamentário: as práticas da Universidade Federal de Lavras. Revista Gestão Universitária na América Latina-GUAL, v. 5, n. 4, p. 209-227, 2012.

SILVA, R. M. Energia Solar no Brasil: dos incentivos aos desafios. Brasília: Núcleo de Estudos e Pesquisas/CONLEG/Senado, fevereiro/2015. [Texto para Discussão n 166].

UNIVERSIDADE ESTADUAL PAULISTA - UNESP. Portal PRPe Indicadores. Disponível em: http://www.unesp.br/PortalPROPe/unesp/fcav/. Acesso em: 15 dez. 2017.

VIER, L. C. et al. Estudo de viabilidade para utilização de placas fotovoltaicas em habitações populares.

Revista gestão e Desenvolvimento em Contexto, v. 5, n. 1, p. 49-52, 2017. 